\title{
Presencia de bacterias Gram positivas en músculo de pescado con importancia comercial en la zona del Caribe mexicano
}

\section{Presence of Gram negative bacteria in fish muscle of commercial importance in the Mexican Caribbean zone}

\author{
Jorge Manuel Romero-Jarero ${ }^{1}$ y María del Pilar Negrete-Redondo ${ }^{2 *}$ \\ ${ }^{I}$ Instituto de Ciencias del Mar y Limnología, Universidad Nacional Autónoma de México. Ciudad Universiraria, Apartado ppostal 70305, Coyoacán \\ 04510 México, D.F., México. \\ ${ }^{2}$ Universidad Autónoma Metropolitana-Xochimilco. Calzada del Hueso 1100, Col. Villa Quietud, Coyoacán 04930 México, D.F., México. \\ *Correspondencia: jordiromeronegrete@hotmail.com
}

\begin{abstract}
Resumen. La presencia de microorganismos patógenos en músculo de especies acuáticas de gran demanda para consumo humano es de alto riesgo para la salud pública. El crecimiento urbano en la costa del Caribe mexicano ha incrementado la contaminación de la zona, por acarreo de residuos. El objetivo del presente estudio fue determinar la diferencia cualitativa y cuantitativa de la carga bacteriana en especies de pescados de importancia comercial, antes y después de procesarse para su comercialización. Se muestreó entre la isla Contoy y bahía de la Ascensión, Quintana Roo, durante la captura y procesado. Se obtuvieron 160 muestras que fueron aisladas y purificadas en agar para Streptococcus y Staphylococcus. Se identificaron siguiendo los criterios de Mc Faddin, y Cowan y Steel. Se aplicó análisis de panel. La contaminación por diferentes especies de Streptococcus y Staphylococcus saprophyticus se registró desde el ambiente de los peces, El manejo durante su comercialización no la incrementó significativamente. El estar conformada por los mismos grupos bacterianos indica contaminación homogénea desde el ambiente marino. Los resultados de este estudio presentan datos valiosos sobre el riesgo que acarrea para la población el consumo de pescado contaminado con esos patógenos en áreas del Caribe mexicano.
\end{abstract}

Palabras clave: bacterias patógenas, Streptococcus, músculo de pescado, contaminación fecal, salud pública, Caribe mexicano.

\begin{abstract}
The presence of pathogenic microorganisms in muscle of aquatic species with high demand for human consumption can be highly dangerous for public health. Urban growth on the Mexican Caribbean coast zones had increased pollution due to urban residues accumulation. The aim of the present study is to determinate qualitative and quantitative differences in bacterial charge of commercial fish species before and after being processed. Samples of the areas between Contoy Island and Bahía de Ascensión, Quintana Roo, were obtained during commercialization, capture and processing. One hundred and sixty samples were isolated and purified in agar Streptococcus and Staphylococcus, and identified according to Mc Faddin, and Cowan and Steel criteria. Results were analyzed by a panel analysis. Contamination with different species of Streptococcus and Staphlococcus were found from marine environment, handling during commercialization does not increase significantly its presence. The presence of same composition of bacterial groups before and after commercialization showed no significant differences, therefore, contamination is present in marine environment. Data from this study provide important evidence of the potential risk for human consuming contaminated fishes with Streptococcus sp. And Staphylococcus sp. collected from the Mexican Caribbean Sea.
\end{abstract}

Key words: pathogenic microorganisms, Streptococcus, muscle of fishes, urban residues, public health, Mexican Caribbean Sea.

\section{Introducción}

El crecimiento de las poblaciones ribereñas y complejos turísticos establecidos en la zona costera del Caribe mexicano,

Recibido: 21 noviembre 2009; aceptado: 06 septiembre 2010 principalmente en Cancún, Tulum, isla Mujeres y Cozumel, han incrementado la contaminación del agua marina. La masa oceánica se ha visto afectada particularmente con las aguas negras que constituyen una fuente de contaminación orgánica (Weibel et al., 1974).

La contaminación del agua marina por aguas domésticas es alta, debido fundamentalmente al acarreo de heces que ocasionan la introducción de bacterias patógenas en 
el medio marino. A pesar de los procesos de dilución y mezcla, estas aguas pueden ser incapaces de reabsorber la contaminación, cuando sus concentraciones rebasan la capacidad autodepuradora del océano (Weibel et al., 1974).

Existen algunas bacterias indicadoras de contaminación con riesgo sanitario, como Staphylococcus aureus, cuyo estudio e identificación es de relevancia para vigilar la calidad higiénica de los productos pesqueros, debido a su importancia como principales productores de infecciones alimentarias, por la gravedad de las enfermedades que provocan, y por el alto número de personas afectadas mundialmente (Moriello et al., 2005).

Asimismo, se sabe que Streptococcus aureus no tolera por mucho tiempo el agua de mar, lo cual va a depender de los factores fisicoquímicos y biológicos del medio marino que pueden determinar la destrucción de las bacterias de origen humano y conferir a este medio un poder autodepurador (Rodríguez y Romero, 1981; Rainhamer, 1990). También se informa que la salinidad es el factor más sobresaliente sobre la viabilidad de las bacterias, cuya pared celular les confiere cierta resistencia a los cambios bruscos en la presión osmótica, mismos que les provocan la muerte (Rodríguez y Romero, 1981; Rainhamer, 1990). Algunas cepas de Staphylococcus sobreviven durante periodos prolongados en aguas saladas, dada su capacidad de crecer en presencia de sal o sin ella. Las cepas tolerantes pueden crecer a concentraciones mayores al 10\%. Durante el tiempo de sobrevivencia los patógenos permanecen virulentos, de aquí que las regiones marinas contaminadas con aguas negras puedan ser peligrosas fuentes de infección (Atlas, 1990).

Los peces y otros organismos marinos que viven en aguas costeras contaminadas poseen una microflora microbiana dependiente de la que existe en las aguas donde viven. Independientemente del tipo de alimentación de los peces (planctónicos, detritívoros, carnívoros, herbívoros), éstos ingieren bacterias en su alimento, encontrándose un gran número de ellas en su tubo digestivo (IzquierdoVicuña, 1981). Las bacterias que se encuentran en la piel y en el contenido gastrointestinal del pez en vida no invaden el paquete muscular estéril, ya que el organismo está protegido por sus defensas naturales. Cuando muere, estas bacterias penetran hacia el interior del pez (Kietzmann et al., 1974). Sin embargo, encuentran que bacterias como S. aureus, involucrada en el síndrome de intoxicación por alimento, puede indicar contaminación a partir de la piel, boca y fosas nasales de los manejadores y técnicos de almacenaje. Las bacterias patógenas entran en contacto con el pescado como consecuencia de la manipulación por personas infectadas o portadores sanos, durante la captura, transporte y procesos de elaboración y preparación.

Por lo tanto, los peces pueden ser considerados como portadores potenciales de bacterias patógenas como la mencionada anteriormente, lo cual resulta de particular importancia en aquellos estados de la República en donde se comercializan los recursos del mar, como es el caso del Caribe mexicano, importante fuente de alimentos principalmente para los lugareños y turistas y en menor proporción para personas de otros lugares de México y de varios países.

La mayoría de las investigaciones que se han realizado en pescado contaminado en su medio natural son extranjeras; en esos estudios se han analizado piel y contenido gastrointestinal de algunos peces marinos. Las especies bacterianas que se han identificado en paquete muscular de estos peces son: Escherichia coli, Enterobacter cloacae, Citrobacter, Salmonella paratyphi A y B, S. enteritidis, $S$. amsterdam, $S$. give, $S$. suipestifer, $P$. vulgaris, $P$. rettgeri, $P$. mirabilis, $P$. morgani, Clostridium botulinum, Enterobacter del grupo C, Serratia sp, Vibrio parahaemolyticus, Streptococcus faecalis, $S$. faecium, $S$. agalactiae, $S$. pyogenes y Staphylococcus epidermidis, entre otros (Gil de Rodríguez y Bastardo, 1975; Morse y Duncan, 1976; Prost, 1977; Austin y Austin, 1986: Agüería et al., 2006). Dichas bacterias no forman parte de la flora normal del intestino del pez y su presencia se considera resultado directo de la asociación de los peces con aguas contaminadas (Volterra et al., 1988). Asimismo, se ha detectado la presencia de coliformes totales, S. aureus y Vibrio parahaemolyticus (Caramello et al., 1986), encontrando que las bacterias predominantes en el pescado procesado varían dependiendo de la temperatura en la que se haya conservado el producto (Fuentes, 1989).

El objetivo del presente estudio fue analizar de manera comparativa la presencia de bacterias en el músculo de peces marinos de interés comercial, en el momento de su captura y del producto procesado para ser comercializado en diferentes puntos del Caribe mexicano.

\section{Materiales y métodos}

El estudio se llevó a cabo en 8 de las principales localidades turísticas y de producción pesquera del Caribe mexicano: isla Contoy, isla Mujeres, Cancún, Puerto Morelos, Playa del Carmen, isla Cozumel, Tulum y bahía de la Ascensión, Quintana Roo, ubicadas entre los $21^{\circ} 15^{\prime} y$ $18^{\circ} 15^{\prime}$ latitud $\mathrm{N}$ y los $86^{\circ} 30^{\prime}$ y $87^{\circ} 30^{\prime}$ longitud O (Contreras et al., 1988), durante el periodo comprendido de julio a octubre de 2008.

Se obtuvieron 20 organismos de cada una de las 11 especies que son consideradas de importancia comercial, de cada una de las zonas anteriormente mencionadas: 10 pescados recién capturados, sin eviscerar y sin ningún 
tipo de procesamiento para su consumo y 10 procesados para su comercialización, recolectados en los mercados locales y cooperativas, donde se encontraban almacenados en charolas de plástico y cubiertos con hielo comercial, 2 horas después de haber sido capturados. Todas las muestras se refrigeraron $\left(4^{\circ} \mathrm{C}\right)$ y se trasladaron al laboratorio para su análisis microbiológico en bolsas estériles de plástico Millipore.

En campo estéril, se limpió previamente la superficie corporal de cada organismo con un algodón empapado con alcohol al 70\%, para posteriormente realizar la disección. Con un bisturí estéril se practicó un corte lateral desde el opérculo hasta la base de la aleta caudal.Ya expuesta la cavidad visceral, se extrajeron muestras de $10 \mathrm{~g}$ de músculo y se homogeneizaron con $90 \mathrm{ml}$ de agua destilada estéril durante 3 minutos, con un homogenizador marca Virtix. Se obtuvo un total de 160 muestras. Se efectuaron diluciones a la décima, desde $10^{-1}$ y hasta $10^{-7}$ (APHA, 1992). De cada frasco de dilución se extrajeron $100 \mu \mathrm{l}$ y se sembraron por duplicado en placas conteniendo medios para Shtaphylococcus, y para Streptococcus.

Para el enriquecimiento de Sthaphylococcus se empleó el medio líquido selectivo tioglicolato (Manual Bioxon, medios de cultivo y reactivos de diagnóstico, 1989) y para el aislamiento y purificación se empleó agar para estafilococos Núm. 110 y base de agar sangre. Se efectuó la técnica de tinción de Gram.

Para la identificación de Sthaphylococcus se siguió el procedimiento de acuerdo con MacFaddin (1981) y Cowan y Steel (1985) y las pruebas bioquímicas complemetarias: catalasa, motilidad, reducción de nitratos, ureasa, D-Nasa (desoxirribonucleasa), fermentación de carbohidratos, licuefacción de la gelatina, Voges-Proskauer y rojo de metilo, formación de pigmento, reacción de la yema de huevo, hemólisis y coagulasa.

Para evaluar si la diferencia en cuanto al número de peces contaminados antes y después de ser procesados para su consumo y la carga bacteriana cualitativa y cuantitativamente de cada especie bacteriana es significativa, se procedió a un análisis estadístico de Panel (Levin y Levin, 1999), para lo cual se planteó la $\mathrm{H}_{\mathrm{n}}$ : $\left(\mu_{\mathrm{PM}}=\mu_{\mathrm{CC}}=\mu_{\mathrm{Is}}=\mu_{\mathrm{T}}=\mu_{\mathrm{PC}}=\mu_{\mathrm{IC}}=\mu_{\mathrm{B}}\right.$ $\left.\mathrm{As}_{\mathrm{As}}=\mu_{\mathrm{IC}}\right)(\mathrm{PM}=$ Puerto Morelos, $\mathrm{CC}=$ Cancún, Is $\mathrm{M}=$ isla Mujeres, $\mathrm{T}=$ Tulum, $\mathrm{PC}=$ Playa del Carmen, $\mathrm{Is} \mathrm{C}=$ isla Cozumel, B As = bahía Ascensión, y I Ct = isla Contoy): no existe diferencia microbiológica cuantitativa o cualitativa, entre los pescados frescos y procesados obtenidos en los 8 puntos de muestreo en el Caribe mexicano.

\section{Resultados}

Las especies de los pescados frescos y procesados que se lograron obtener en los diferentes puntos de muestreo anteriormente mencionados pertenecen a las especies Calamos pennatula (mojarra), Caranx crysos (cojinuda), Epinephelus morio (mero), Haemulon plumieri (chaecchi), Larimus argenteus (boquinete), Lutjanus campechanus (liseta), Lutjanus synagris (pargo), Mycteroperca bonaci (abadejo), Scomberomorus maculatus (sierra), Mugil curema (lisa) y Seriola dumerili (coronado) (Cuadro 1). Se procesaron un total de 152 muestras: 72 pescados frescos y 80 procesados, de los cuales, 38 de los primeros y 26 de los segundos registraron presencia de carga bacteriana.

Se aislaron e identificaron 4 especies de bacterias de la familia Streptococcaceae: S. faecalis, S. faecium, S. salivarius y $S$. mutans. De la familia Micrococcaceae únicamente se aisló la especie Sthaphylococcus saprophyticus. Estas especies se aislaron tanto de pescado fresco (38) como del procesado (26). La especie de bacteria que manifestó mayor presencia fue $S$. faecalis (en 23 pescados frescos y 15 procesados), seguida de: $S$. saprophyticus con 5 pescados frescos y 1 procesado, $S$. faecium con 4 y 8 , S. salivarius 3 y 2 y $S$. mutans con 3 y 0 , respectivamente (Cuadro 2).

De igual forma, el promedio de unidades formadoras de colonias por mililitro $(\mathrm{ufc} / \mathrm{ml})$ fue concordante con lo antes observado, habiéndose registrado $2 \times 10^{8} \mathrm{ufc} / \mathrm{ml} \mathrm{de} S$. faecalis en muestras de pescado fresco y $8 \times 10^{6}$ en muestras de pescado procesado y $1 \times 10^{6}$ y $7 \times 10^{4} \mathrm{ufc} / \mathrm{ml} \mathrm{de} S$. faecium, respectivamente. Para $S$. salivarius se cuantificó menor cantidad de bacterias en pescado procesado $\left(1 \times 10^{2}\right.$ $\mathrm{ufc} / \mathrm{ml})$ que en el fresco $\left(4 \times 10^{3} \mathrm{ufc} / \mathrm{ml}\right)$, condición que se repite para $S$. mutans con 0 presencia de ufc $/ \mathrm{ml}$ en pescado procesado y $4 \times 0^{4} \mathrm{ufc} / \mathrm{ml}$ en pescado fresco.

De esta forma, las $\mathrm{t}_{\text {obtenida }}=2.3, \mathrm{t}_{\text {obtenida }}=3.3$ para los niveles de confianza $\mathrm{P}_{05}$ y $\mathrm{P}_{.01}$ respectivamente y $\mathrm{Gl}=8$ (Cuadro 4), llevan a aceptar la Hn: $\left(\mu_{\mathrm{PM}=} \mu_{\mathrm{CC}=} \mu_{\mathrm{Is} \mathrm{M}=} \mu_{\mathrm{T}=} \mu_{\mathrm{PC}=}\right.$ $\mu_{\mathrm{IC}=} \mu_{\mathrm{BAs}=} \mu_{\mathrm{I}=\mathrm{CT}}$ (no existe diferencia significativa en la carga bacteriana cualitativa y cuantitativa entre los diferentes pescados, frescos y procesados, identificados, y entre los diferentes puntos de muestreo en el Caribe mexicano).

\section{Discusión}

El presente estudio demuestra la contaminación de origen antropogénico en músculo de peces de importancia comercial en el Caribe mexicano, problema por demás importante debido a que la zona de estudio tiene gran afluencia turística y porque muchas veces la carne se consume cruda o en el mejor de los casos a baja temperatura de cocción.

La presencia de especies de bacterias Gram negativas, S. faecalis, S. saprophyticus, S. faecium; S. salivarius; y 


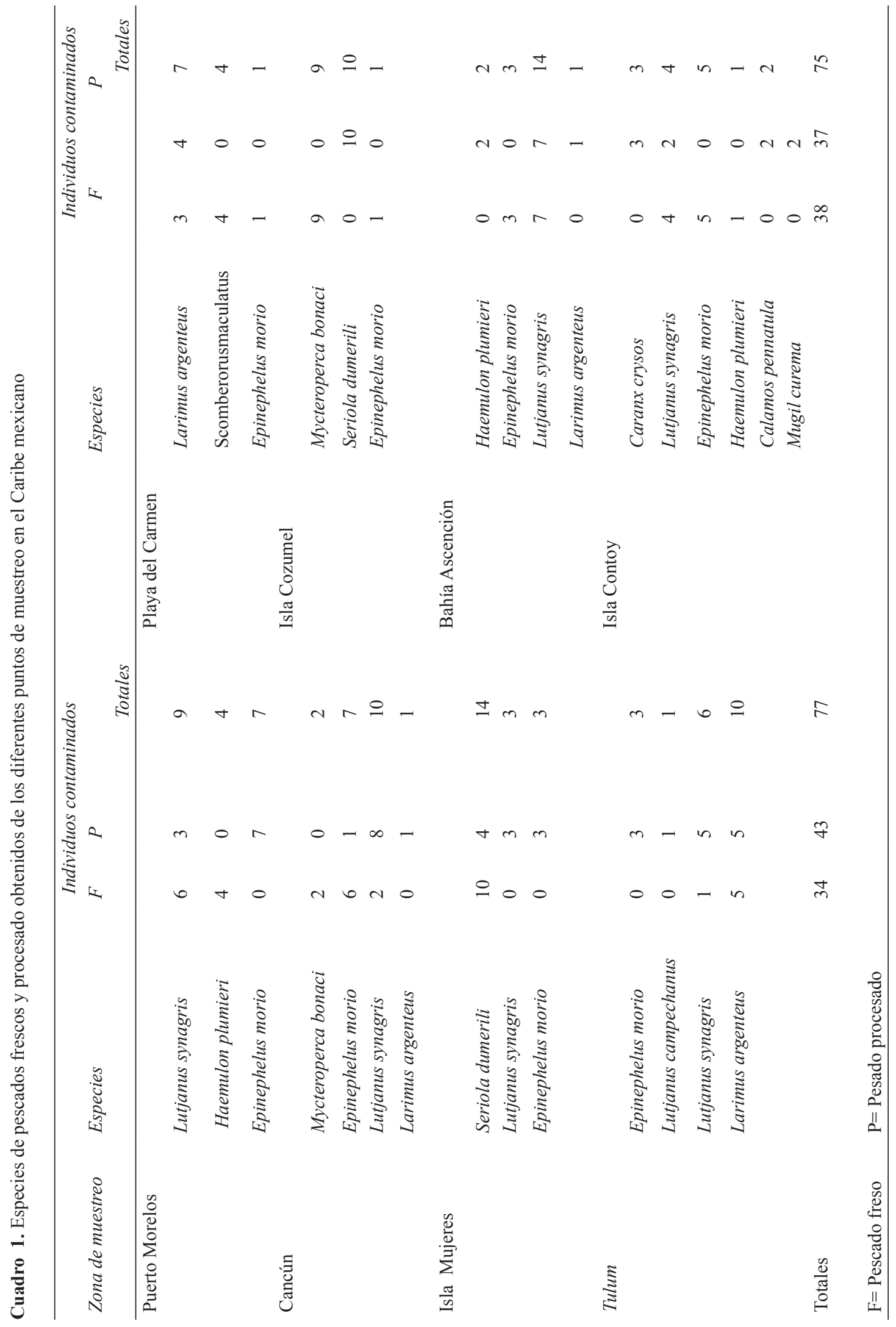


Cuadro 2. Especies bacterianas identificadas en las muestras de pescado fresco y procesado en la costa del Caribe mexicano

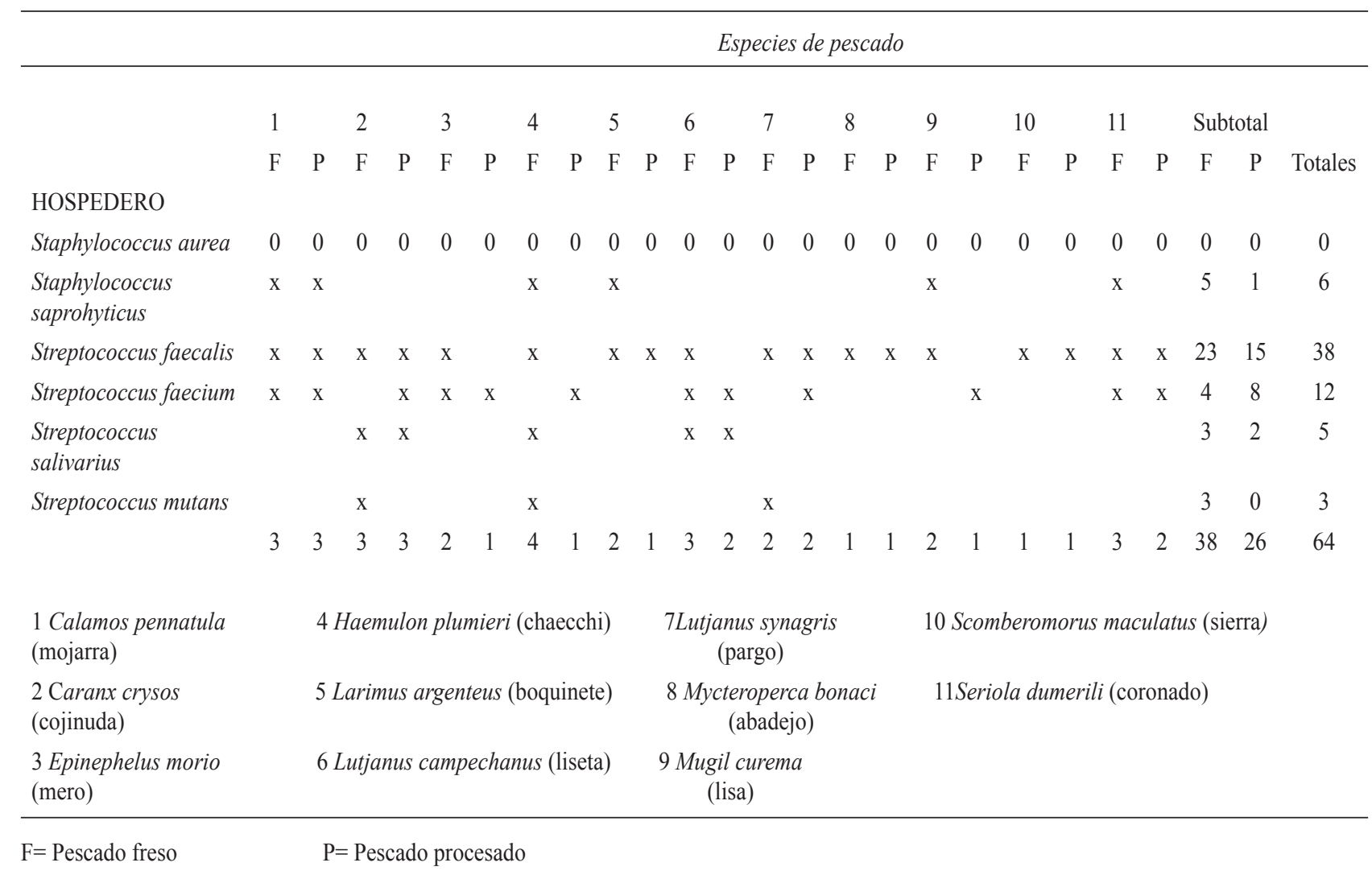

S. mutans, tanto en pescado fresco como procesado, llevó a aceptar que no existe diferencia significativa en la carga bacteriana cuantitativa y cualitativa en los pescados antes o después de ser procesados para su comercialización, que la diferencia que se registró puede deberse a error de muestro, o bien, a que los pescados pasan por un proceso de lavado durante su comercialización. De igual forma, no existe diferencia significativa entre los pescados capturados en las 8 zonas de muestreo. Sin embargo, era de esperarse que las muestras de mercado presentaran mayor incidencia, ya que durante la manipulación se incrementa el contenido bacteriano, debido a que los estafilococos se encuentran ampliamente diseminados en el medio ambiente y, por lo general, el humano es portador de esta bacteria en la piel, fosas nasales y cavidad bucal (Kingsbury et al., 1989).

Los resultados negativos con respecto a $S$. aureus coagulasa positiva, probablemente se deban a que estuvo presente en el músculo de los peces pero en baja cantidad, ya que su detección en los productos alimenticios depende del número de microorganismos presentes capaces de producir las enterotoxinas responsables de la estafiloenterocoxis en el humano (Mosell et al., 1971), lo cual se ha comprobado en una gran variedad de estudios que se han realizado acerca de la calidad higiénica del pescado. Por lo tanto, el hecho de que no se haya identificado en el muestreo se puede considerar como relativo, porque es probable que la especie estuviera presente en pequeñas cantidades, que al ser sometidas al proceso de enriquecimiento fueron desplazadas por los grupos bacterianos más abundantes.

A pesar de que se utilizaron medios selectivos para obtener el desarrollo abundante de Sthaphylococcus, se desarrollaron más sus competidoras, ya que generalmente existen en los cultivos bacterianos mezclas microbianas con requerimientos nutricionales similares, por lo que normalmente crecen varios tipos de organismos, predominando, entonces, aquellos que fueron más abundantes y con mayor capacidad adaptativa. Por lo tanto, se presentó crecimiento de otros tipos bacterianos en el $37 \%$ de las muestras, pertenecientes a las familias Microccaceae, género Shtaphylococcus, y Streptococcaceae, género Streptococcus.

El grupo predominante fue Streptococcus, formado por el $93.3 \%$ de las bacterias aisladas en el presente estudio; las especies de este género se encuentran en el grupo de bacterias patógenas más importantes, ya que causan una alta morbilidad en el humano; son oportunistas, aprovechando 
Cuadro 3. Análisis cuantitativo (ufc/ml) promedio de especies de las familias Micrococcaceae y Strptococcaceae, registradas en pescado fresco y procesado del Caribe mexicano

Número de individuos

Fresco procesados

Hospedero

Staphylococcus aurea

Staphylococcus saprohyticus

Streptococcus faecalis

Streptococcus faecium

Streptococcus salivarius

Streptococcus mutans

$\mathrm{cfu} / \mathrm{ml}$, unidades formadoras de colonias por $\mathrm{ml}$

$\begin{array}{ll}0 & 0 \\ 8 \times 10^{6} & 1 \times 10^{2} \\ 2 \times 10^{8} & 8 \times 10^{6} \\ 1 \times 10^{4} & 7 \times 10^{6} \\ 4 \times 10^{3} & 5 \times 10^{2} \\ 3 \times 10^{4} & 0\end{array}$

$3 \times 10$

Cuadro 4. Valores de significancia $t$ para la carga bacteriana registrada en pescado antes y después de ser procesado para su
comercialización comercialización

\begin{tabular}{lccc}
\hline & $\begin{array}{c}t_{\text {obtenida }} \\
P=0.01\end{array}$ & $\begin{array}{c}t_{\text {calculada }} \\
P=0.05\end{array}$ & 0.76 \\
\hline $\begin{array}{l}\text { Diferencia entre las 8 zonas de muestreo } \\
\begin{array}{l}\text { Diferencia de la carga bacteriana entre las diferentes especies de } \\
\text { pescado analizado }\end{array}\end{array}$ & 2.3 & 3.3 & 0.35 \\
$\begin{array}{l}\text { Diferencia entre grupos bacterianos identificados } \\
\text { Diferencia en carga cuantitativa (ufc/ml) }\end{array}$ & 2.4 & 3.1 & 0.66 \\
\end{tabular}

$\mathrm{Gl}=$ Grados de libertad

los nutrientes y las condiciones presentes en el medio $\mathrm{y}$ compiten por espacio con las demás bacterias. La fuente de aislamiento de $S$. faecalis son las heces, por lo que para fines del presente estudio y de acuerdo con Carballo (1985) se le considera indicadora de contaminación fecal crónica; es un habitante común de las vías respiratorias, vías genitouterinas y tubo gastrointestinal de los humanos. Entre las enfermedades que provoca se encuentra la peritonitis, infecciones biliares y del aparato urinario (Starr et al., 1981). Al no ser exigentes nutrimentalmente, proliferan en casi todos los medios bacteriológicos; lo anterior, junto con su resistencia a las condiciones adversas del ambiente marino, determinó que fuera una de las especies más frecuentes en ambos tipos de muestra.

Streptococcus faecalis se ha identificado en ostión y en varias especies de peces. Su uso como indicador de contaminación fecal, según Kusuda y Komatsu (1978) y Austin y Austin (1986), no es tan frecuente; sin embargo, la abundancia con la que se presentó en las muestras en el presente estudio y las enfermedades que provoca, lo hacen un grupo indicador fecal importante. Streptococcus salivarius y $S$. mutans, son habitantes comunes de la boca y conducto intestinal del humano; el primero es un organismo exigente en sus requerimientos nutricionales, ricos en proteínas, causa caries dental y endocarditis bacteriana y el segundo se considera de mayor virulencia, provoca caries dental, formación de sarro y endocarditis bacteriana (Austin y Austin, 1986). La especie menos representada, $S$. saprophyticus, forma parte de una de las 3 especies del género de mayor importancia médica; 
se localiza normalmente en la piel y fosas nasales de los humanos y es causante de serias infecciones de las vías urinarias (Starr et al., 1981). No se ha comprobado con certeza el tiempo que sobrevive en el agua de mar, pero sí se ha demostrado que puede subsistir por mucho tiempo en este ambiente y en el aire (Kingsbury et al., 1989).

El análisis bacteriológico realizado evidenció que las muestras de pescado recién capturado también presentaron crecimiento bacteriano. Lo anterior demuestra que los peces desde que están en el medio ambiente natural se encuentran contaminados por bacterias patógenas de origen humano y animal y su manejo en el mercado no incrementa significativamente su contaminación (Cuadro 3).

Los peces recién capturados en las 8 localidades presentaron contaminación por bacterias patógenas en mayor o menor grado; las estaciones con los porcentajes de contaminación más altos fueron bahía de la Ascensión, isla Contoy e isla Mujeres. Se observó que la incidencia bacteriana en los pescados analizados en este estudio, no fue selectiva, es decir, no se presentó mayor o menor tendencia de ciertas especies bacterianas, a contaminar sólo alguna o algunas especies de pescados en especial.

El conocimiento de los resultados obtenidos en el presente trabajo está circunscrito a 3 aspectos de gran importancia: 1) el económico, ya que en esta zona hay importantes pesquerías de escama que reducen su calidad con la presencia de los patógenos identificados. Además, los productos pesqueros mexicanos no se pueden colocar en un nivel competitivo con los productos de exportación; 2) el impacto sobre poblaciones naturales, que generalmente no sólo involucra la contaminación de peces, sino en general la de organismos marinos y del ecosistema, y 3) la amenaza sanitaria que representan los peces como vectores de bacterias patógenas. El consumo de pescado $y$ mariscos contaminados ha causado epidemias en el país, en los Estados Unidos, en Perú y en las zonas del Mediterráneo (Sayler et al., 1975; Cortesi y Della, 1977 y Levin, 1978).

\section{Literatura citada}

Agüeria, D., A. Grosman, P. Tabera, P. Sanzano y R. Porta. 2004. Valoración de la calidad de carne de pejerrey Odontesthes bonariensis. Revista Aquatica 20:9-19

Atlas, R. M. 1990 Microbiología, fundamentos y aplicaciones. Continental, México, D.F. 887 p.

Austin, B. y D.A. Austin, 1986. Bacterial pathogens of fish. Journal of Applied Bacteriology. 58:483-506.

APHA. 1992. Standard methods for examination of water and waste water.17th. American Public Health Association, Washington, D. C. 799 p.
Carballo, C. 1985. Caracterización de bacterias heterótrofas en los aportes de la laguna de Términos en la Sonda de Campeche. Tesis, Facultad de Química, Universidad Nacional Autónoma de México. $145 \mathrm{p}$.

Caramello, S., G. Amisano, E. Adriano F. Maury y L. Borea. 1986. Results of a microbiological study on fishery products. IG. MOD. 86:257-278.

Contreras. F., M. Herzig, y V. Botello. 1988. Atlas del golfo y Caribe de México. Diagnóstico ambiental. Secretaría de Pesca, México, D. F. 44 p.

Cortesi, My G. Della. 1977. Indagini microbiologicite quantitative su mitili vivi del comercio. Archivos de Veterinaria Italiana 28:205-211

Cowan, S. T. y J. Steel. 1985. Manual para la identificación de bacterias de importancia médica, segunda edición. Continental, México, D. F. 320 p.

Fuentes, L. 1989. Determinación del grado de frescura de la mojarra blanca (Diapterus olisthostomus) entera y eviscerada almacenada en hielo. Tesis, Facultad de Química, Universidad Nacional Autónoma de México, México, D. F. $95 \mathrm{p}$.

Gil de Rodríguez, T. y J. W Bastardo. 1975. Investigation of enterobacteria in the gastrointestinal tract of corocoro, Orthopristis ruber (Pisces, Perciformes, Pomadasydae). Boletín del Instituto de Oceanografía de la Universidad de Oriente. 14:149-156.

Izquierdo-Vicuña, B. 1981.Estudio monográfico acerca de la microbiología marina. Monografía. Tesis, Facultad de Química, Universidad Nacional Autónoma de México, México, D.F. 255 p.

Kietzmann, V., K. Pruebe y D. Rakow. 1974. Inspección veterinaria de pescados.1 Acribia, Zaragoza. 326 p.

Kingsbury, T. D., G. Wagner. y P. Segal. 1989. Microbiología médica. Limusa, México, D.F. 505 p.

Kusuda, R. y Y. Komatsu. 1978. Comparative study of fish pathogenic Streptococcus isolated from saltwater and freshwater fishes. Bull Japanese Society Scientific Fishery 44:1073-1078.

Levin, M. 1978. Fish and shellfish associated disease outbreaks. Journal of Water Pollution. Control Federal. 50:377-1381.

Levin, M, y W. Levin, . 1999 .Fundamentos de estadística en la investigación social. Oxford University. México, México, D. F. 375 p.

Mac Faddin, J. F. 1981. Biochemical tests for identification of medical bacteria second edition. Williams and Wilkins, Baltimore, Maryland. 527 p.

Manual de bacteriología Bioxón. 1989. Medios de cultivo y reactivos de diagnóstico. Bioxón de México, México, D.F. 87 p.

Morse, E. y M. Duncan. 1976. Salmonella as monitors of fecal pollution in the aquatic environment. Part. A. Journal of Environmental Sciences. Health 11:591-601.

Mosell, D., A. Ratto y L. Indacochea. 1971. El control de la calidad 
microbiológica en la industria alimentaria. Barcelona 6:45.

Moriello, N., R. Finol, V. Kutchynskaya y C. A. Soto. 2005.

Evaluación bacteriológica y organoléptica en dos especies de pescados del lago de Maracaibo, Venezuela. Revista Científica Veterinaria Tropical 2:1-3

Prost, M. 1977. Fish as a source of infections and parasitic infestations in man Medicina Veterinaria 33:641-646.

Rainhamer, G. 1990. Aquatic microbiology. Springer, Berlin.325 p.

Rodríguez, S. H. y J .J. Romero. 1981. Niveles de contaminación bacteriana en dos sistemas fluvio-lagunares asociados a la laguna de Términos, Campeche. Anales del Instituto de Ciencias del Mar y Limnología, Universidad Nacional Autónoma de México 8:63-68.
Sayler, G., A. Nelson y R. Colwell. 1975. Distribution and significance of fecal indicator organisms in the upper Chesapeake bay. Apply Microbiology. 30:625-638.

Starr, H., H. Stolp, H. G. Truper, A. Balows y H.G. Schlegel. 1981. The prokaryotes. A handbook on habitats, isolation and identification of bacteria, vol. ii. Springer, Berlin, Heidelberg, New York. 218 p.

Volterra L., I. Manzini, F.A. Zulicino y S. Marilungo. 1988. Fish as vectors of microorganisms. Journal of Microbiology. 90:782-795.

Weibel, S., J. Anderson y R. Woodward. 1974. Urban land runoff as a factor in stream pollution. Journal of Water Pollution. 36:914-924. 